\title{
Sympatho-adrenal hyperactivity-the key to irreversible shock?
}

\author{
M. H. IRVING* \\ Dudley Road Hospital, Birmingham
}

\begin{abstract}
Summary
There would appear sound evidence on which to incriminate sustained sympatho-adrenal hyperactivity as a deleterious factor of prime importance in hypovolaemic shock. The use of sympathomimetics in the treatment of shock of this type is irrational and deleterious. Their rational use in those few cases of clinical shock where they are indicated will have to await knowledge of plasma catecholamine levels in such cases.

Experimental studies involving $\alpha$ - and $\beta$-adrenergic blockade, unilaterally and in combination, have revealed that, contrary to previous theories, deterioration is mediated through both receptor types.

Many of the current concepts of the pathophysiology of shock will need reassessment in the light of as yet unappreciated facets of catecholamine activity.
\end{abstract}

\section{Introduction}

Of all the homeostatic mechanisms initiated by acute hypovolaemic hypotension the most important would appear to be an intense activation of the sympatho-adrenal system. Outpourings of adrenaline from the adrenal medulla and noradrenaline from the post-ganglionic sympathetic nerve-endings constitute the most immediate and most effective protective mechanism and are responsible for the majority of the physical signs observed in clinical shock.

This activation of the sympatho-adrenal system has been the subject of extensive experimental investigation, the results of which have led to the incorporation into current clinical therapy of techniques involving both adrenergic stimulation and adrenergic blockade.

It is the purpose of this communication to discuss some facets of sympatho-adrenal function in shock and to consider both its place in the development of the so called 'irreversible' state and its relationship to clinical therapy.

The extent of adrenergic activity in experimental shock states

Despite the relative unreliability of methods used for measuring plasma catecholamines a broad level

\footnotetext{
*Present address: North Middlesex Hospital, London.
}

of agreement has been obtained by workers who have investigated plasma adrenaline and noradrenaline levels in states of hypovolaemic and endotoxic shock. Walton et al. (1959) recorded a mean adrenaline level of $64 \mu \mathrm{g} / 1$ in dogs subjected to haemorrhagic shock which corresponded with findings subsequently published by Rosenberg et al. (1961). A similar rise occurs in noradrenaline levels but these invariably constitute a lesser fraction (20-40\%) of the total catecholamine content (Lund, 1951).

In certain instances the level of catecholamine in shock reaches exceptionally high values. Walton et al. (1959) observed an adrenaline level of $220 \mu \mathrm{g} / 1$ in a case of experimental haemorrhagic shock whilst Rosenberg et al. (1959) recorded an adrenaline level of $457 \cdot 2 \mu \mathrm{g} / 1$ in a case of experimental endotoxin shock.

Sequential studies of catecholamine levels in experimental haemorrhagic shock have demonstrated that they become maximal soon after haemorrhage commences and remain high throughout the period of hypotension (Watts \& Bragg, 1957), only falling on correction of hypovolaemia or at the onset of the 'irreversible' stage.

The question of whether this fall in catecholamine levels, occurring just prior to the irreversible stage, represents an exhaustion of the sympatho-adrenal system and is responsible for death remains controversial. In support of such reasoning Hift \& Campos (1962) demonstrated the depletion of the myocardial noradrenaline stores in dogs dying from irreversible haemorrhagic shock. On the other hand Walker et al. (1959) and Glaviano, Bass \& Nykiel (1960) have shown that plasma catecholamine levels are still higher in dogs dying from irreversible haemorrhagic shock than in healthy control animals.

The factors that stimulate the increased output of catecholamines and maintain the elevated levels observed in shock have likewise been the subject of much investigation. The initial stimulus is undoubtedly neurogenic, hypotension causing reflex autonomic activity which is conveyed to the adrenal medulla via the greater splanchnic nerves (Beck \& Dontas, 1955). The adrenomedullary response in such circumstances is thus largely abolished by section of the greater splanchnic nerves (Tachi, 1928). Once hypotension is established other factors 
develop which stimulate further secretion. Amongst these are said to be metabolic acidosis (Malm et al., 1966), anoxia (Walton et al., 1959) and hypovolaemia (Fowler, Shabetai \& Holmes, 1961). Catecholamine levels remain high throughout shock because of continued release of hormones from the adrenal medulla and not because of interference with the mechanisms that remove them from the plasma. Adrenalectomy during hypovolaemia causes the complete disappearance of adrenaline from the plasma (Watts, 1965).

Knowledge of plasma catecholamine levels in clinical shock and preterminal states is remarkably scanty. Rhoads \& Howard (1963) have, however, documented urinary adrenaline and noradrenaline levels in man after trauma and demonstrated that the levels are highest $8 \mathrm{hr}$ after injury and may remain high for several days.

\section{Adrenergic hyperactivity in shock: is it deleterious?}

It is obvious that the initial adrenergic response to acute hypovolaemic hypotension is a vital homeostatic mechanism without which the organism is less able to tolerate the stresses to which it is subjected. Indeed the inhibition of this compensatory response in an incompletely resuscitated patient, e.g. by anaesthesia, may precipitate a cardiovascular collapse.

Two principal observations however, aroused the suspicion that sustained sympatho-adrenal activity in such circumstances could be deleterious. The first resulted from investigations of the effect of prolonged adrenaline and noradrenaline infusion into healthy animals. Using this technique several workers, notably Bainbridge \& Trevan (1917), Freeman (1933) and Watts \& Westfall (1964), produced states of irreversible hypotension comparable with those seen after protracted haemorrhagic hypotension. The similarities between haemorrhagic and adrenalineinfusion shock are noteworthy. In both a profound metabolic acidosis occurs, due principally to a rise in lactic acid, together with anuria and a paralytic ileus. In dogs both stimuli cause portal hypertension, haemorrhagic necrosis of the intestine and a progressively rising haematocrit in the irreversible stage, said to be the result of plasma loss.

The similarity between the two conditions stimulated Watts \& Westfall (1964) to compare the catecholamine levels in each. They found that a continuous infusion of $3.4 \mu \mathrm{g} / \mathrm{kg} / \mathrm{min}$ of adrenaline sustained a plasma adrenaline level of $39 \mu \mathrm{g} / \mathrm{l}$ and produced a state of irreversible hypotension culminating in death. They commented that if this plasma level of adrenaline alone was enough to cause a fatal outcome then surely the level of $46.1 \mu \mathrm{g} / 1$ of endogenous catecholamine observed in haemorrhagic hypotension must in itself be of significance.
The second observation, stimulated to a large extent by the knowledge that infusion of adrenaline $\frac{\widehat{D}}{\mathbb{D}}$ caused irreversible hypotension, was that surgically sympathectomized animals, although reduced to a lower level of blood pressure by a measured blood $\underset{\vec{S}}{\vec{F}}$ loss compared with intact animals, did not become $\overline{0}$ as acidotic nor did they as readily relapse into irrever- 흘 sible shock (Freeman et al., 1938). Other workers $\frac{\overline{\bar{p}}}{\vec{D}}$ using varying techniques to achieve sympathetic $\mathbb{\nabla}$ denervation subsequently verified these observations (Kleinberg et al., 1942; Eversole et al., 1944).

The immediate assumption was that the benefit in $\overrightarrow{0}$ these cases was obtained by prevention of compen- $\overrightarrow{\vec{H}}$ satory vasoconstriction with consequent maintenance of tissue perfusion and tissue nutrition. Thus parallel to these somewhat crude surgical $\frac{O}{3}$ experiments the more refined method of pharmacologically induced vasodilatation was investigated. of Beginning with ergot, and progressing to dibenamine 용 and phenoxybenzamine, considerable investigation of of the effects of vasodilator therapy upon experimen- N tally induced haemorrhagic and endotoxin shock $\mathrm{O}$ was undertaken.

\section{Mechanisms in catecholamine-induced deterioration}

Although Ahlquist (1948) who laid the foundations of the modern adrenergic receptor concept had $\vec{\theta}$ clearly nominated two receptor types $(\alpha$ and $\beta)$ a the mediators for adrenergic activity, the questiof of adrenergic mechanisms in shock has been domp nated by the role of the $\alpha$ receptor. Deterioration has, apparently quite logically, been attributed to the vasoconstriction - tissue-underperfusion - tissuehypoxia cycle (Fig. 1).

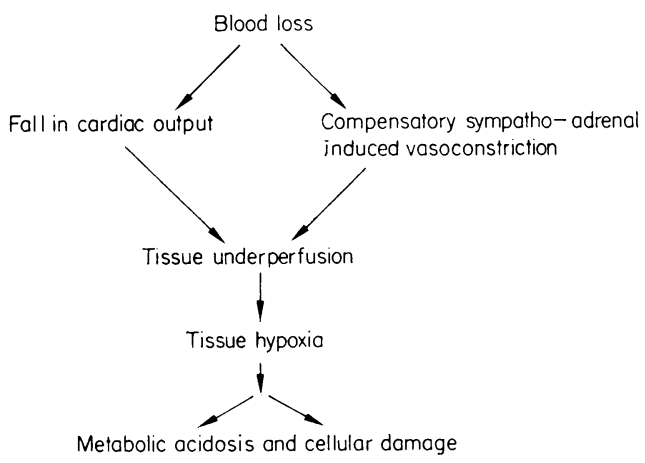

FIG. 1

It followed that to prevent or reverse the vaso- N constrictive element would be a logical supportive 0 measure in improving the tolerance to shockinducing stimuli. Support for this concept was forth- $\frac{\mathbb{\Phi}}{\overparen{D}}$ coming from Wiggers et al. (1947), who found that $\stackrel{\infty}{+}$ the $\alpha$-blocking agent, dibenamine, gave protection 0 against the development of irreversible shock if $\underset{\mathbb{D}}{\circ}$ 
administered to an animal prior to the onset of haemorrhagic hypotension.

These findings were supported by Remington et al. (1948), since when numerous other workers have attested the value of this and the newer $\alpha$-adrenergic blocking agents in preventing the development of irreversible shock if given as a premedication prior to many forms of shock-inducing stimuli.

There is almost universal agreement that administration of $\alpha$-blocking agents after the onset of shock does not give similar protection to that demonstrated by premedication, and in many cases causes rapid deterioration. It is probably because of this that the use of $\alpha$-blocking agents in clinical shock has, by and large, been so disappointing.

Not all workers, however, were able to obtain this benefit by using prophylactic $\alpha$-adrenergic blockade, some actually recording a deterioration in the resistance of the animals so treated (Ingraham, Roemhild \& Goldberg, 1948; Brandfonbrenner \& Geller, 1952; Rush, Rosenberg \& Spencer, 1965) whilst Baue, Johnson \& Parkins (1966) found that far from reducing the extent of the shock-induced metabolic acidosis (usually accepted as an index of tissue perfusion) $\alpha$-adrenergic blockade made it worse.

In our own experiments (Halmagyi, Gillett \& Irving, 1967a; Halmagyi et al., 1967b; Irving, 1968; Irving et al., 1968) we have, in common with these latter workers, shown that premedication with phenoxybenzamine does not protect against either the metabolic acidosis or the onset of irreversible shock in both severe haemorrhagic and adrenalineinfusion shock.

It is only recently, since the advent of the $\beta$ adrenergic blocking agents, that attention has been directed to the role of $\beta$-receptor activity in shock. Berk et al. (1967) suggest that excessive $\beta$ activity by creating vasodilatation in the splanchnic and pulmonary areas is primarily responsible for the deterioration into the irreversible state seen after sustained haemorrhagic hypotension. They claim that $\beta$-adrenergic blockade with propranolol is capable of preventing the haemorrhagic pulmonary and splanchnic vascular congestion observed in dogs subjected to haemorrhagic hypotension, and thus increases the resistance to irreversible change. Their results have, however, to be assessed against the fact that such profound dilatation in the splanchnic region is a species-specific character that is not observed in sheep, primates or man. Additionally it must be remembered that their results were only achieved after myocardial function had been supported with atropine, digitalis and calcium, whilst profound hypoglycaemia had been corrected with glucose infusion.

The foregoing results together with our own experiments convinced us that unilateral receptor blockade was, by and large, ineffectual in preventing the fundamental lesions caused by sympathoadrenal hyperactivity. It thus appeared logical to completely block adrenergic activity by using $\alpha$ and $\beta$-blocking agents in combination.

The reasoning appeared to be confirmed when, using both sheep and dogs, we demonstrated that premedication with $\alpha$ - and $\beta$-adrenergic blocking agents in combination so improved the tolerance of the animals that they were able to survive periods of haemorrhagic hypotension and adrenaline infusion which would prove fatal to non-medicated animals (Halmagyi et al., 1967a). In addition the experiments revealed an adrenergic basis for facets of the shock syndrome that are not normally connected with catecholamine activity. Thus the rise in plasma lactic acid normally observed in haemorrhagic hypotension was markedly curtailed, whilst the anuria and paralytic ileus that usually accompany the shock state were prevented. It remains to be seen whether, as we suspect, other aspects of the shock syndrome such as osmolality and coagulation-mechanism changes are likewise dependent upon catecholamine activity.

It was particularly noteworthy that in animals under combined $\alpha$ - and $\beta$-blockade cardiovascular dynamics and responses were more like those of non-medicated control animals than in those with unilateral blockade. Thus, the fact that there was near-normal vasoconstrictive activity in the animals under combined blockade suggests that current theories implicating sustained vasoconstriction and tissue underperfusion as the cause of metabolic acidosis and irreversible shock need reassessment.

In support of this our observation that $\alpha$-blockade, although markedly reducing the vasoconstrictive response to haemorrhage and abolishing it in adrenaline infusion does not affect the extent of the metabolic acidosis, is undoubtedly of significance. This is in striking contrast with the animals under combined adrenergic blockade, who in spite of a fall in oxygen uptake develop no or minimal acidosis (Halmagyi et al., 1967a).

If, as we believe, this means that metabolic acidosis is the result of factors other than tissue underperfusion and tissue hypoxia a review of its allegedly deleterious effects is indicated.

Whatever the actual mechanism of adrenergicinduced deterioration it is clear that it is mediated through both receptor types. Future work must look at the problem of irreversible cellular damage at a much more fundamental level than the present vasoconstriction-tissue underperfusion-theory.

\section{The clinical application}

As long ago as 1895 Oliver \& Schafer were quick to advocate the use of their newly discovered extract 
of adrenal gland in the treatment of circulatory failure on the grounds that it caused a sharp rise in blood pressure.

This pattern of thinking has in the past dominated the treatment of shock and sympathomimetics were widely used to raise the arterial blood pressure in hypotensive patients. It is only recently that the importance of adequate plasma volume expansion has been stressed and the deleterious effects of pressor therapy fully recognized. Those who still advocate the use of sympathomimetics in shock states claim they do so more because of their effects upon the myocardium than upon the peripheral circulation.

There would nowadays be few clinicians who would advocate sustained sympathomimetic infusion in the treatment of traumatic, endotoxic or hypovolaemic shock. Indeed it may be said that the use of such agents in these conditions, where plasma catecholamines have been shown experimentally to be extremely high, would not only be unphysiological but frankly deleterious. Their use in cardiogenic shock is more difficult to assess for it cannot be denied that in some cases their exhibition has been of distinct value. Rational clinical use of sympathomimetics in shock states will have to await knowledge of actual plasma catecholamine levels in the varying types of clinical shock.

The unilateral boosting of $\beta$-adrenergic activity holds a special place in this respect. It has been shown experimentally by Halmagyi, Horner \& Starzecki (1965) and clinically by du Toit et al. (1966), that the short-term selective boosting of $\beta$-activity with isoprenaline is of value in embolic and endotoxin shock. The beneficial effect appears to stem from the increase in cardiac output, combined with pulmonary vascular and bronchial dilatation, in a condition where the cardinal pathogenetic factor is a profound pulmonary vasoconstriction. This phenomenon appears to be in a category of its own and the use of sustained infusions of isoprenaline in shock states is probably as illogical as the similar use of other sympathomimetics.

In contrast the use of adrenergic blocking agents in the treatment of shock is still a largely untried form of therapy. There is little doubt that in some shocked patients where, after adequate transfusion, a high central venous pressure is associated with arterial hypotension and evidence of peripheral vasoconstriction, the use of an $\alpha$-blocking agent, such as phenoxybenzamine, is of value. The benefit from phenoxybenzamine in such circumstances is probably obtained in a different manner from that demonstrated in animal experiments. In the latter circumstances blockade is applied to a healthy, normotensive, normovolaemic animal thereby preventing the vasoconstrictive response to haemorrhage. In the clinical setting described phenoxybenz- amine probably acts by countering the continuing sympatho-adrenal-induced vasoconstriction and thereby allowing the full extent of the functional hypovolaemia to be revealed and corrected. In this way 'normovolaemia' and normotension are restored and adrenergic activity curtailed.

There would not appear to be any grounds for advocating $\beta$-adrenergic blockade in the treatment of shock.

Although combined $\alpha$ - and $\beta$-blockade is already used in the management of patients with phaeochromocytoma it, as yet, has no place in the management of the shocked patient. Indeed we have shown in our experiments that the administration of combined blockade to an animal already in shock is associated with cardiovascular collapse and death. Its future lies in further experimental work by revealing fully the role of catecholamines in the physiology and biochemistry of shock. It may find clinical application in the premedication of patients who are likely to be exposed for long periods to high catecholamine levels, such as in cardiac bypass.

\section{References}

AHLQUist, R.R. (1948) A study of the adrenotropic receptors. Amer. J. Physiol. 153, 586.

Bainbridge, F.A. \& Trevan, J.W. (1917) Surgical shock and some allied conditions. Brit. med. J. 1, 381.

Baue, A., Johnson, D.G. \& Parkins. W.M. (1966) Bloods flow and oxygen consumption with adrenergic blockade in hemorrhagic shock. Amer. J. Physiol. 211, 354.

BECK, L. \& DonTAS, A.S. (1955) Vasomotor activity in hemorrhagic shock. Fed. Proc. 14, 318.

Berk, J.L., Hagen, J.F., Beyer, W.H., Dochat, G.R. \& La PoINTE, R. (1967) The treatment of hemorrhagic shock by beta adrenergic receptor blockade. Surg. Gynec. Obstet. $125,311$.

Brandfonbrenner, M. \& Geller, H.M. (1952) Effect of dibenamine on renal blood flow in hemorrhagic shock. Amer. J. Physiol. 171, 482.

Du Toit, H.J., Du Plessis, J.M.E., Dommisse, J., RoRke, M.J., Theron, M.S. \& DE Villiers, V.P. (1966) Treatment of endotoxin shock with isoprenaline. Lancet, ii, 143.

Eversole, W.J., Kleinburg, W., Overman, R.R., RemingTON, J.W. \& SWINGLE, W.W. (1944) The nervous factor in shock induced by muscle trauma in normal dogs. Amer. J. Physiol. 140, 490.

Fowler, N.O., Shabetai, R. \& Holmes, J.C. (1961) Adrenal medullary secretion during hypoxia, bleeding and rapid intravenous infusion. Circulat. Res. 9, 427.

Freeman, N.E. (1933) Decrease in blood volume after prolonged hyperactivity of the sympathetic nervous system. Amer. J. Physiol. 103, 185.

Freeman, N.E., Shaffer, S.A., Schecter, A.E. \& Holling, H.E. (1938) The effect of total sympathectomy on the occurrence of shock from hemorrhage. J. clin. Invest. 17, 359.

Glaviano, V.V., Bass, N. \& Nykiel, F. (1960) Adrenal medullary secretion of epinephrine and norepinephrine in dogs subjected to hemorrhagic hypotension. Circulat. Res. 8, 564.

Halmagyi, D.F.J., Gillett, D.J. \& Irving, M.H. (1967a) Partial and 'complete' adrenergic blockade in post hemorrhagic shock. J. appl. Physiol. 22, 487. 
Halmagyi, D.F.J., Horner, G.J. \& Starzecki, B. (1965) Acute cor pulmonale and shock. Med. J. Aust. 2, 141.

Halmagyi, D.F.J., Irving, M.H., Gillett, D.J. \& Varga, D. (1967b) Effect of adrenergic blockade on consequences of sustained epinephrine infusion. J. appl. Physiol. 23, 171.

HifT, H. \& Campos, H.A. (1962) Changes in subcellular distribution of cardiac catecholamines in dogs dying in irreversible haemorrhagic shock. Nature (Lond.), 196, 678.

INGRAHAM, R.C., ROEMHILD, F. \& GOLDBERG, H. (1948) Further observations on the effect of pentobarbital and of an adrenolytic agent upon the survival of animals subjected to a procedure resulting in experimental hemorrhagic shock. Fed. Proc. 7, 60.

IRVING, M.H. (1968) The sympatho-adrenal factor in haemorrhagic shock. Ann. roy. Coll. Surg. Lond. 13, 300.

Irving, M.H., Varga, D., Gillett, D.J. \& Halmagyi, D.F.J. (1968) The effect of adrenergic blockade upon shock-induced lacticacidosis in sheep. Brit. J. Surg. 55, 780.

Kleinberg, W., Remington, J.W., Drill, V.A. \& Swingle, W.W. (1942) The nervous factor in the circulatory failure induced in adrenalectomized dogs by intestinal stripping and a single stage bilateral adrenalectomy. Amer. J. Physiol. 137, 362.

LuND, A. (1951) Release of adrenaline and noradrenaline from the suprarenal gland. Acta. pharmacol. $(K b h), 7,309$.

Malm, J.R., Manger, W.M., Sullivan, S.F., PaPPer, E.M. \& NAHAS, G.G. (1966) The effect of acidosis on sympathoadrenal stimulation. J. Amer. med. Ass. 197, 121.

Oliver, G. \& Schafer, E.A. (1895) The physiological effects of extracts from the suprarenal capsules. J. Physiol. (Lond.), $18,230$.

Remington, J.W., Wheeler, N.C., Boyd, G.H. \& Caddell, H.M. (1948) Protective action of dibenamine after hemorrhage and muscle trauma. Proc. Soc. exp. Biol. (N.Y.), 69, 150.

RhoAds, J.E. \& HowARD, J.M. (1963) The Chemistry of Trauma. Thomas, Springfield, Illinois.
Rosenberg, J.C., Lillehei, R.C., Longerbeam, J. \& ZimmerMAN, B. (1961) Studies on hemorrhagic and endotoxin shock in relation to vasomotor changes and endogenous circulating epinephrine, norepinephrine and serotonin. Ann. Surg. 154, 611.

Rosenberg, J.C., Lillehei, R.C., Moran, W.H. \& ZimmerMAN, B. (1959) Effects of endotoxin on plasma catecholamines and serum serotonin. Proc. Soc. exp. Biol. (N.Y.), 102, 335.

Rush, B.F., Rosenberg, J.C. \& Spencer, F.C. (1965) Effect of dibenzyline treatment on cardiac dynamics and oxidative metabolism in hemorrhagic shock. Ann. Surg. 162, 1013.

TACHI, H. (1928) Influence of hemorrhage upon the epinephrine (Folin) content of the suprarenals of the rabbit. Tokohu J. exp. Med. 10, 409.

Walker, W.I., Zileli, M.S., Reutter, F.W., Shoemaker, W.C., Friend, D. \& Moore, F.D. (1959) Adrenal medullary secretion in hemorrhagic shock. Amer. J. Physiol. 197, 773.

Walton, R.P., Richardson, J.A., Walton, R.P., JR \& Thомpson, W.L. (1959) Sympathetic influences during hemorrhagic hypotension. Amer. J. Physiol. 197, 223.

WatTs, D.T. (1965) Adrenergic mechanisms in hypovolemic shock. Shock and Hypotension. Grune \& Stratton, New York.

WATTS, D.T. \& BRAGG, A.D. (1957) Blood epinephrine levels and automatic reinfusion of blood during hemorrhagic shock in dogs. Proc. Soc. exp. Biol. (N.Y.), 96, 609.

Watts, D.T. \& Westfall, V. (1964) Studies on peripheral blood catecholamine levels during hemorrhagic shock in dogs. Proc. Soc. exp. Biol. (N.Y.), 115, 601.

Wiggers, H.C., Roemhild, F., Goldberg, H. \& Ingraham, R.C. (1947) The influence of prolonged vasoconstriction on the transition from impending to irreversible hemorrhagic shock. Fed. Proc. 6, 226. 